\title{
Endoscopic mucosal resection: Early experience in British Columbia
}

\author{
Mayur Brahmania MD, Eric Lam MD, Jennifer Telford MD, Robert Enns MD
}

\begin{abstract}
M Brahmania, E Lam, J Telford, R Enns. Endoscopic mucosal resection: Early experience in British Columbia. Can J Gastroenterol 2010;24(4):239-244.
\end{abstract}

BACKGROUND: Endoscopic mucosal resection (EMR) has been proposed as a primary method of managing patients with dysplasia- or mucosal-based cancers of the esophagus.

OBJECTIVES: To evaluate the use of EMR for the treatment of Barrett's esophagus with dysplasia or early adenocarcinoma, assessing efficacy, complication rates and long-term outcomes.

METHODS: All patients who underwent EMR at St Paul's Hospital (Vancouver, British Columbia) were reviewed. Eligible patients were assessed with aggressive biopsy protocols. Detected cancers were staged with both endoscopic ultrasound imaging and computed tomography. Appropriate patients were offered EMR using a commercially available mucosectomy device. EMR was repeated at six-to eight-week intervals until complete. Patients with less than one year of follow-up or who were undergoing other ablative methods were excluded.

RESULTS: Twenty-two patients (all men) with a mean $( \pm \mathrm{SD})$ age of $67 \pm 10.6$ years were identified. The mean duration of gastroesophageal reflux disease was 17 years (range four to 40 years) and all were receiving proton pump inhibitor therapy. The mean length of Barrett's esophagus was $5.5 \pm 3.5 \mathrm{~cm}$. One patient had no dysplasia (isolated nodule), three had low-grade dysplasia, 15 had high-grade dysplasia (HGD) and three had adenocarcinoma. A mean of $1.7 \pm 0.83$ endoscopic sessions were performed, with a mean of $6 \pm 5.4$ sections removed. Following EMR, three patients developed strictures; two of these patients had pre-existing strictures and the third required two dilations, which resolved his symptoms. There were no other complications. Three patients underwent esophagectomy. Two had adenocarcinoma or HGD in a pre-existing stricture. The third patient had an adenocarcinoma not amenable to EMR. One patient with a long segment of Barrett's esophagus underwent radiofrequency ablation. At a median follow-up of two years (range one to three years), the remaining 18 patients $(82 \%)$ had no evidence of HGD or cancer. CONCLUSION: Most patients with esophageal dysplasia can be managed with EMR. Individuals with pre-existing strictures require other endoscopic and/or surgical methods to manage their dysplasia or adenocarcinoma.

Key Words: Barrett's esophagus; EMR; Esophagectomy; High-grade dysplasia

$\mathrm{B}$ arrett's esophagus is believed to be a complication of longstanding gastroesophageal reflux disease (GERD), resulting in the replacement of the normal squamous lining of the distal esophagus by columnar epithelium, also known as specialized intestinal metaplasia (SIM). Endoscopic surveillance is recommended for patients with Barrett's esophagus because of its malignant potential. However, management of Barrett's

\section{Résection muqueuse endoscopique : Application précoce en Colombie-Britannique}

HISTORIQUE : La résection muqueuse endoscopique (RME) a été proposée comme méthode principale pour la prise en charge des patients atteints de cancers de l'œsophage intra-épithéliaux ou intramuqueux.

OBJECTIF : Faire état de notre expérience avec l'utilisation de la RME pour le traitement de l'oesophage de Barrett avec dysplasie ou de l'adénocarcinome précoce, en évaluant son efficacité, ses taux de complications et ses résultats à long terme.

MÉTHODES : Les dossiers de tous les patients ayant subi une RME à l'Hôpital St. Paul (Vancouver, Colombie-Britannique) ont été passés en revue. Les patients admissibles ont subi des évaluations au moyen d'un protocole rigoureux de biopsies. Les cancers dépistés ont été stadifiés par échographie endoscopique et tomographie. On a offert aux patients appropriés une RME à l'aide d'un appareil à mucosectomie. La RME a été répétée après six ou huit semaines jusqu'à ce qu'elle soit complète. Les patients qui avaient été suivis pendant moins de un an ou qui avaient subi d'autres méthodes ablatives ont été exclus.

RÉSULTATS : Vingt-deux patients (tous des hommes), âgés en moyenne ( \pm É. T.) de $67 \pm 10,6$ ans, ont été recensés. La durée moyenne de leur RGO était de 17 ans (allant de quatre à 40 ans) et ils recevaient tous un traitement par inhibiteur de la pompe à protons. La longueur moyenne de l'œsophage de Barrett était de 5,5 $\pm 3,5 \mathrm{~cm}$. Un patient ne présentait aucune dysplasie (nodule isolé), trois présentaient une dysplasie de bas grade, 15 , une dysplasie de haut grade (DHG) et trois, un adénocarcinome. Les patients ont subi en moyenne $1,7 \pm 0,83$ séances endoscopiques pour une moyenne de $6 \pm 5,4$ segments réséqués. Après la RME, trois patients ont présenté des strictures, mais deux en étaient déjà porteurs et le troisième a nécessité deux dilatations qui ont soulagé ses symptômes. On n'a noté aucune autre complication. Trois patients ont subi une œsophagectomie, deux souffraient d'adénocarcinome ou de DHG au niveau d'une stricture préexistante. Le troisième patient présentait un adénocarcinome réfractaire à la RME. Un patient présentant un long segment d'œsophage de Barrett a subi une ablation de radiofréquence. Après un suivi médian de deux ans (entre un et trois ans), les 18 patients restants (82\%) ne présentaient aucun signe de DHG ou de cancer.

CONCLUSION : La plupart des patients qui présentent une dysplasie œsophagienne peuvent être pris en charge par RME. Les patients qui présentent déjà des strictures ont besoin d'autres méthodes endoscopiques et/ou chirurgicales pour la prise en charge de leur dysplasie ou de leur adénocarcinome.

Department of Medicine, Division of Gastroenterology, St Paul's Hospital, University of British Columbia, Vancouver, British Columbia

Correspondence: Dr Robert Enns, Pacific Gastroenterology Associates, Suite 770-1190 Hornby Street, Vancouver, British Columbia V6Z 2 K5.

Telephone 604-688-6332 ext 222,fax604-689-2004,e-mail renns@interchange.ubc.ca

Received for publication July 8, 2009. Accepted August 27, 2009 


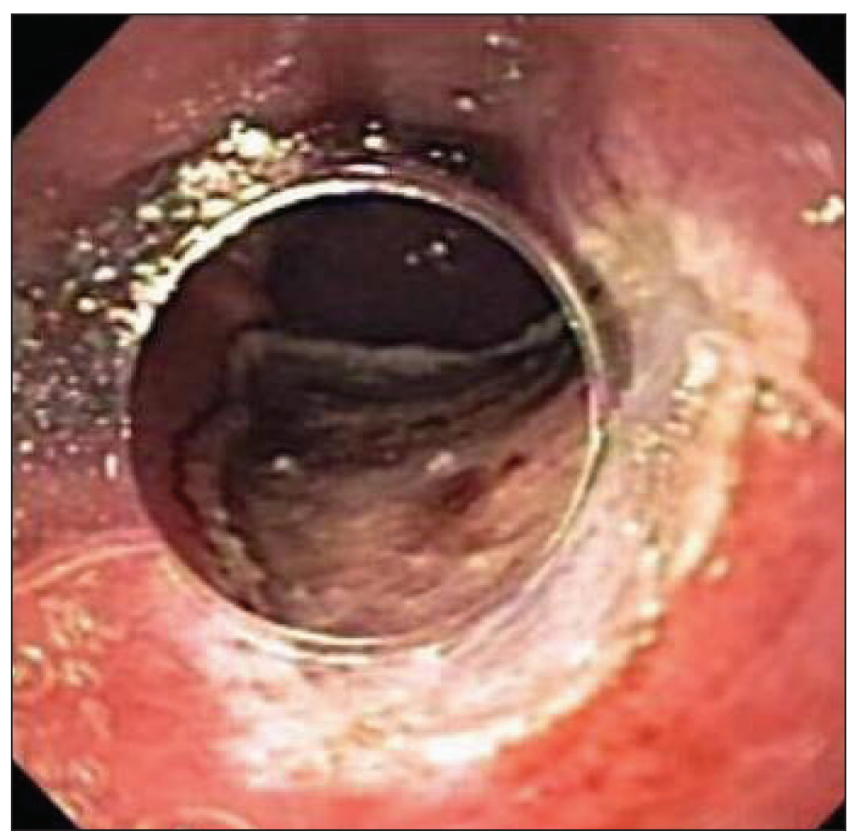

Figure 1) Endoscopic mucosal resection. Endoscopic view through a bander

long-term functional problems such as dysphagia may persist $(3,4)$. The high mortality and morbidity rates associated with esophagectomy have encouraged the development of endoscopic techniques to manage dysplastic epithelium.

Photodynamic therapy (PDT) is based on the ability of chemical agents, known as photosensitizers, to produce cytotoxicity in the presence of oxygen after stimulation by light of an appropriate wavelength. Although advantages include ease of use and cost when compared with surgery (5-7), longterm data comparing esophagectomy and PDT are comparable. An observational study (8) involving 199 patients with fiveyear follow-up found similar survival rates between PDT and esophagectomy (overall mortality $9 \%$ versus $8.5 \%$, respectively). Moreover, PDT for HGD reduces, but does not eliminate, the risk of progression to cancer because recurrences may be high as $13 \%$ despite treatment (9). Disadvantages include photosensitivity, which may last for six weeks, and symptomatic esophageal strictures.

Radiofrequency ablation (RFA) is a newer method for treating HGD. RFA uses radiofrequency energy delivered by a balloon fitted with a series of closely spaced electrodes (10). Thermal destruction of cells at a controlled depth results in low rates of stricture formation and buried metaplasia, which are the main advantages of ablative therapy. Initial results for this system are promising (11-13); however, ablative techniques do not permit identification of foci of invasive carcinoma not detected in biopsy samples which, in turn, may not have been treated adequately.

Endoscopic mucosal resection (EMR) of the esophagus has been proposed as a suitable method for managing patients with either HGD or intramucosal cancers $(14,15)$ (Figure 1). We describe our experience using EMR for the treatment of Barrett's esophagus with dysplasia or intramucosal adenocarcinoma, assessing long-term effectiveness and complications.

\section{METHODS}

All patients referred to St Paul's Hospital (Vancouver, British Columbia) from 2004 to 2007 with Barrett's esophagus exhibiting either dysplasia (both HGD and low-grade dysplasia [LGD]) or early adenocarcinoma were considered for EMR and included in the analysis. St Paul's Hospital is a tertiary care facility and is a provincial referral hospital for therapeutic endoscopy (including EMR). All procedures were performed by one experienced endoscopist (RE). Patients were identified in the electronic medical system and their charts were systematically reviewed. Demographic data including age, sex, duration of reflux, use of proton pump inhibitor therapy and history of other endoscopic interventions (eg, dilation for stricture) were collected. Patients were excluded if they had less than one year of follow-up or had undergone other ablative procedures such as PDT or RFA.

\section{EMR}

Patients were sedated with intravenous midazolam and meperidine as per St Paul's Hospital conscious sedation guidelines. Patients were staged with an aggressive biopsy protocol using 'jumbo' forceps to biopsy every centimetre of four quadrants of Barrett's esophagus. Individuals with adenocarcinoma underwent endoscopic ultrasound imaging and computed tomography scanning for staging. Patients with dysplasia or early adenocarcinoma were offered EMR using a multiband mucosectomy device (Duette, Cook Medical, USA). Using the endoscopic banding resection technique, no submucosal injection was used. The lesion was directly aspirated into the cap and snared with a hexagonal snare with standard electrocautery settings. Resected specimens of all 22 patients were recovered in their entirety. There was no limit to the number of resections per session; however, circumferential resections (Figure 2) were avoided. EMR was repeated at six - to eightweek intervals until there was no endoscopic evidence of HGD on biopsy. Patients were then surveyed with the biopsy protocol every three to six months. If there was no evidence of dysplasia at six months, patients were followed annually.

\section{Analysis}

The primary outcome measure of interest was the effectiveness of EMR in treating dysplastic changes associated with Barrett's esophagus. Effectiveness was defined as no LGD on endoscopic biopsies after two years. The secondary outcome was complications. Because this was a retrospective, observational study, results were presented as descriptive statistics. Means \pm SDs were used to report continuous variables following a normal distribution. Medians with ranges were used to report nonnormal continuous variables.

Written approval for the study was obtained from the local ethics committee, conducted in accordance with the Declaration of Helsinki.

\section{RESULTS}

Twenty-two patients with Barrett's esophagus and HGD or adenocarcinoma who underwent EMR were identified. The mean age of the patients was $67 \pm 10.6$ years, all of whom were men. All patients were on a proton pump inhibitor and reported a median GERD history of 17 years (range four to 40 years). The mean length of Barrett's esophagus was $5.5 \pm 3.5 \mathrm{~cm}$ (Table 1 ). 


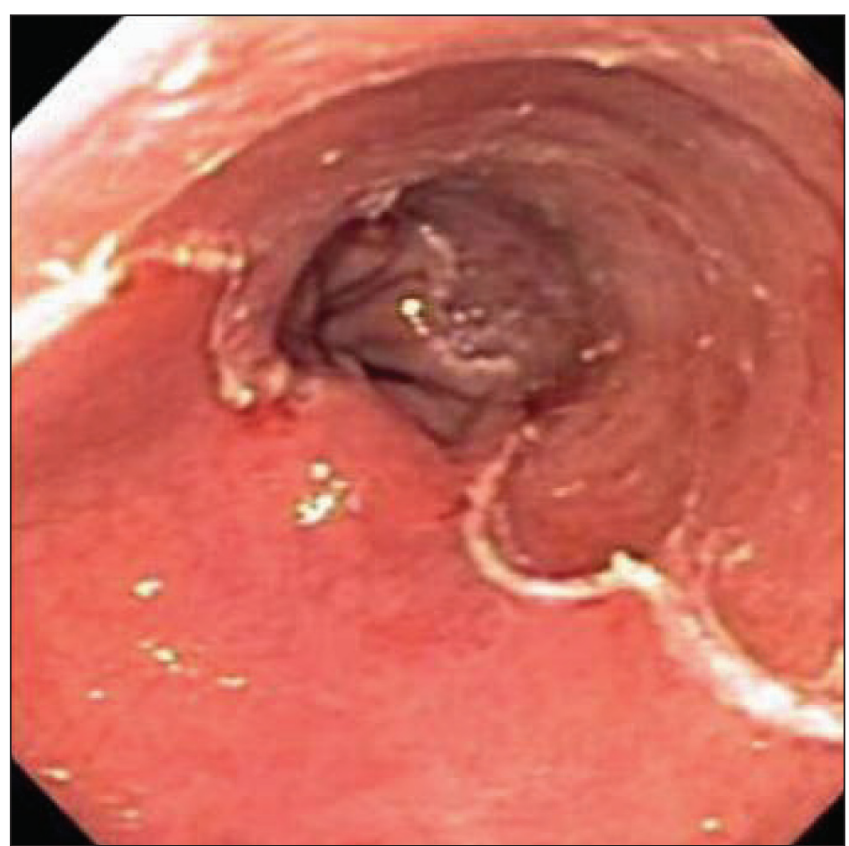

Figure 2) Semicircumferential endoscopic mucosal resection

One patient had no dysplasia (nodule), three had LGD, 15 had HGD and three had adenocarcinoma - all in the distal esophagus. A mean of $1.7 \pm 0.83$ endoscopic sessions were performed with a mean of six (range one to 26) sections removed in total. Three patients developed strictures following EMR; two of whom had pre-existing strictures, and the third required two dilations under conscious sedation, which completely relieved the symptoms. None of the patients sustained a perforation or hemorrhage following EMR.

Three patients in the study underwent subsequent esophagectomy. Two were patients with pre-existing strictures (as above). One had a focus of mucosal malignancy within the stricture; the other had an area of HGD within the stricture. The third patient had an adenocarcinoma not amenable to EMR because it was located in a hiatus hernia distal to the squamocolumnar junction. Following EMR, one patient underwent RFA to treat a long-segment Barrett's esophagus (Figure 3).

The remaining 18 patients were followed for a median of two years (range one to three years). Fourteen patients had no dysplasia and four had focal LGD, and continued in a surveillance program. At the time of the present report, no patient had died or developed cancer (Table 2).

\section{DISCUSSION}

EMR of the esophagus has been proposed to be an ideal method for the management of patients with either dysplasia- or mucosal-based cancers $(14,15)$. EMR involves excision of esophageal mucosa to the level of the submucosa by applying a band (ie, suctioning mucosa to create a 'pseudopolyp') then excising and collecting the tissue. It serves both a diagnostic and therapeutic role while minimizing hospital stays and morbidity.

The Japan Gastroenterological Endoscopy Society has developed a classification system (16) to help define the indications and outcomes of EMR based on visual and endosonographic features. Ideally, those most suitable for EMR are
TABLE 1

\section{Patient characteristics}

\begin{tabular}{lc}
\hline Age, years & $67 \pm 10.6$ \\
Duration of heartburn, years, median (range) & $17(4-40)$ \\
Barrett's esophagus length, cm & $5 \pm 3.5$ \\
Endoscopic mucosal resection sessions & $1.7 \pm 0.83$ \\
Endoscopic mucosal sections removed & $6 \pm 5.4$ \\
\hline
\end{tabular}

Data presented as mean $\pm S D$ unless indicated otherwise

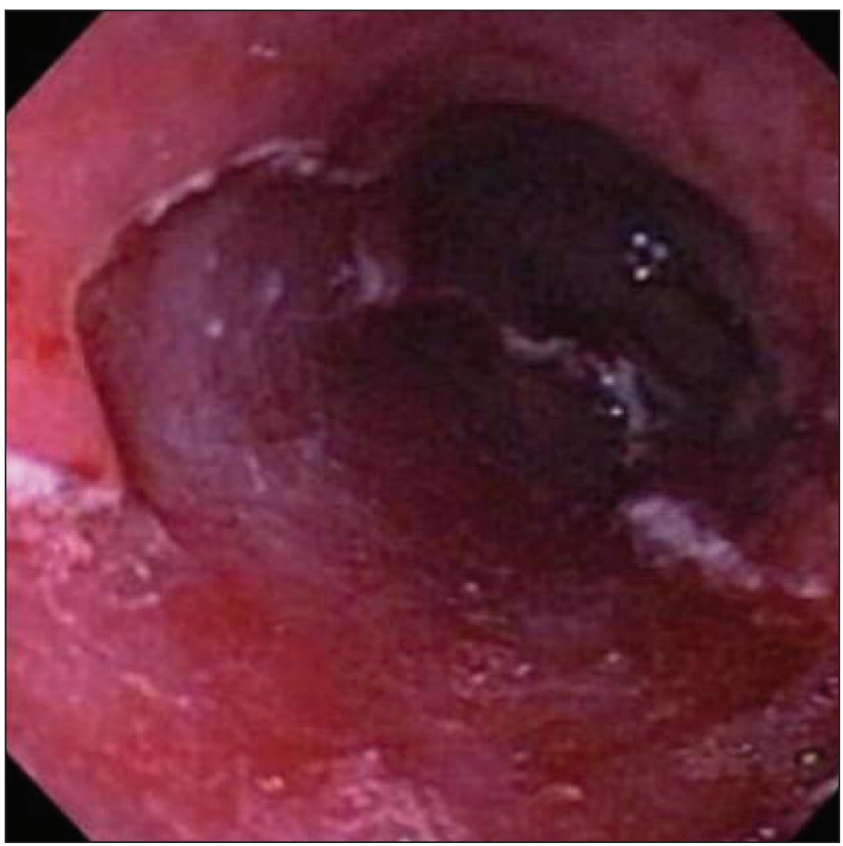

Figure 3) Long-segment endoscopic mucosal resection

individuals with a lesion of $2 \mathrm{~cm}$ or less in diameter, limited to the mucosa and involving less than one-third of the circumference of the esophagus. A helpful modality for planning EMR is endoscopic ultrasound because it enables the determination of tumour insertion depth and the assessment of regional as well as celiac lymph nodes.

A variety of EMR techniques for the treatment of Barrett's esophagus have been described. The most widely used technique is the endoscopic cap resection technique. The target lesion is first lifted by injection of a fluid sometimes containing dilute adrenaline into the submucosa. Subsequently, a transparent cap is attached to the endoscope. The cap has a distal ridge that enables positioning of a snare. The lesion is sucked into the cap thus creating a pseudopolyp that is immediately captured by forcefully closing the prepositioned snare. Finally, the lesion is removed using electrocoagulation. An alternative approach (the 'suck band-and-cut technique') does not require submucosal injection. A reusable variceal ligation device is used to suck the lesion into the ligation cap, allowing it to be captured with a rubber band. The endoscope is then removed, the ligation device is disassembled, and the endoscope is reintroduced to remove the created pseudopolyp with a standard polypectomy snare. A prospective randomized study (17) found no significant difference with respect to the size of the resected specimens or complications among the first two described techniques. Several new techniques are currently 


\begin{tabular}{|c|c|c|}
\hline \multirow[b]{2}{*}{ Patient } & \multicolumn{2}{|c|}{ Endoscopic mucosal resection } \\
\hline & Pre & Post \\
\hline 1 & High-grade dysplasia & No dysplasia \\
\hline 2 & High-grade dysplasia & Low-grade dysplasia \\
\hline 3 & Adenocarcinoma & No dysplasia \\
\hline 4 & Nodule & Low-grade dysplasia \\
\hline 5 & High-grade dysplasia & No dysplasia \\
\hline 6 & High-grade dysplasia & High-grade dysplasia (surgery) \\
\hline 7 & High-grade dysplasia & No dysplasia \\
\hline 8 & Adenocarcinoma & No dysplasia \\
\hline 9 & High-grade dysplasia & No dysplasia \\
\hline 10 & High-grade dysplasia & Adenocarcinoma (surgery) \\
\hline 11 & Adenocarcinoma & Adenocarcinoma (surgery) \\
\hline 12 & High-grade dysplasia & Low-grade dysplasia \\
\hline 13 & High-grade dysplasia & No dysplasia \\
\hline 14 & High-grade dysplasia & No dysplasia \\
\hline 15 & High-grade dysplasia & No dysplasia \\
\hline 16 & High-grade dysplasia & No dysplasia \\
\hline 17 & High-grade dysplasia & No dysplasia \\
\hline 18 & Low-grade dysplasia & Low-grade dysplasia \\
\hline 19 & Low-grade dysplasia & Radiofrequency ablation \\
\hline 20 & High-grade dysplasia & No dysplasia \\
\hline 21 & High-grade dysplasia & No dysplasia \\
\hline 22 & Low-grade dysplasia & No dysplasia \\
\hline
\end{tabular}

being developed, which may reduce the time and cost required for procedures while reducing patient discomfort and enabling many endoscopists to perform EMR.

Several studies from Europe and Japan (18-22) have demonstrated the safety and efficacy of EMR; however, the use of EMR in Canada has largely been unreported until now. Longterm data concerning recurrence rates are still somewhat lacking; however, published data regarding EMR of isolated lesions have been favourable thus far (23-30). In a German study, Ell et al (22) documented 100 consecutive patients who were considered to have low-risk Barrett's carcinoma and reported remission in 99 patients after a maximum of three resections. During a median follow-up period of 37 months, recurrent or metachronous cancers were found in $11 \%$ of patients who were all effectively treated endoscopically. In the largest study to date (31), Japanese researchers investigated 142 patients with esophageal cancer who were followed for nine years and reported a 95\% survival rate using EMR.

Complications, however infrequent, are worth mentioning because they can lead to increased morbidity and health care costs and discourage the widespread use of EMR. Therapies such as esophagectomy may be associated with high morbidity and mortality rates with long-term problems such as dysphagia $(1-4)$. PDT is associated with a $30 \%$ rate of stricture formation (32) and data regarding long-term complications from RFA techniques are lacking. EMR offers less morbidity and mortality, while being associated with fewer complication rates (Figures 4 to 6). Perforation is a rare (1\%) but serious complication that has been found to increase with piecemeal resection (32). Stricture formation is also of concern; however, strictures

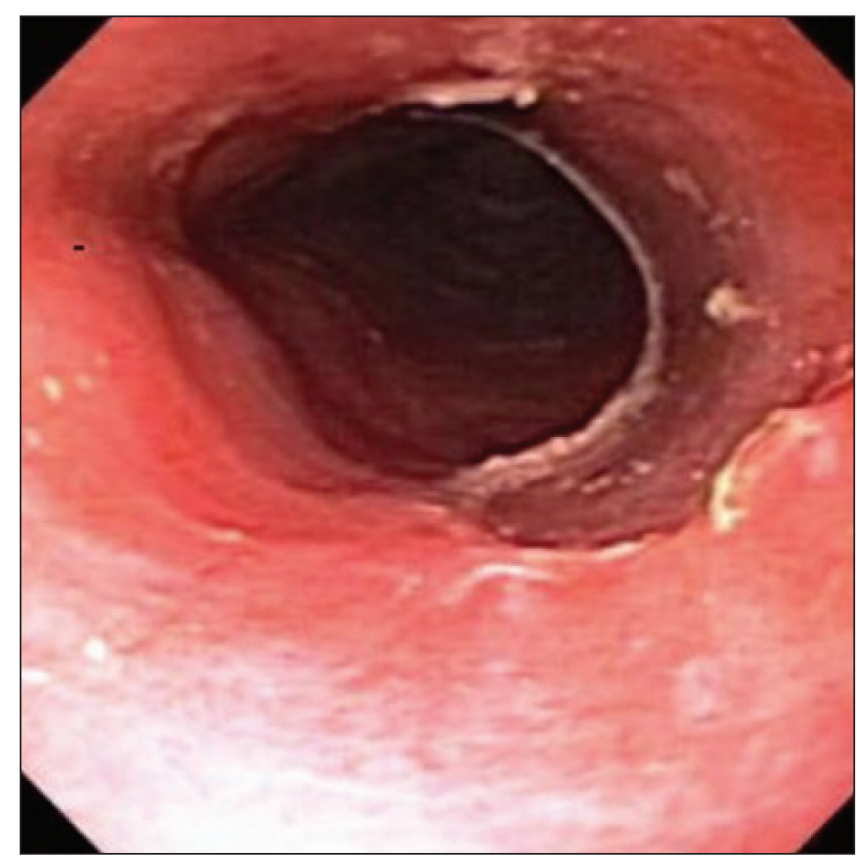

Figure 4) Postendoscopic mucosal resection

tend to occur in patients in whom the EMR involves more than three-fourths of the circumference of the esophagus or when the resection length is greater than $3 \mathrm{~cm}$ (33). Nevertheless, most strictures are amenable to endoscopic dilation (33).

Our patients were treated with monotherapy EMR. We believed it was important to assess our results, particularly because newer methods of therapy (such as RFA) have become available. Although we have several patients with focal LGD remaining, there have been no major complications. Some of our patients with longer segments of remaining Barrett's esophagus or LGD may be considered for RFA or ongoing surveillance. Although the early data for RFA appear to be very promising, the cost of this treatment exceeds that of EMR, particularly for short-segment lesions. Presently, we have adjusted our management protocol using RFA (usually in combination with EMR) for long segments or those segments that are resistant to EMR. For short-segment HGD/mucosal cancers, we still advocate monotherapy with EMR, typically removing all Barrett's esophagus over two or three endoscopic sessions.

\section{CONCLUSIONS}

Most patients with localized lesions of the esophagus, particularly in shorter segments of Barrett's esophagus, can be managed with endoscopic mucosal resection. EMR is preferable to modalities such as esophagectomy and PDT, offering lower morbidity and mortality rates while achieving acquisition of the entire specimen. Longer segment Barrett's esophagus remains an issue, and other ablative therapies such as RFA appear promising. The need for specialized centres capable of performing EMR and regular endoscopic follow-up, along with the complications of EMR such as bleeding, stricture and perforation, have hindered the widespread use of EMR in Canada. Further studies need to be conducted to define the cost-benefit ratio of EMR as opposed to other modalities, as well as to study the long-term 


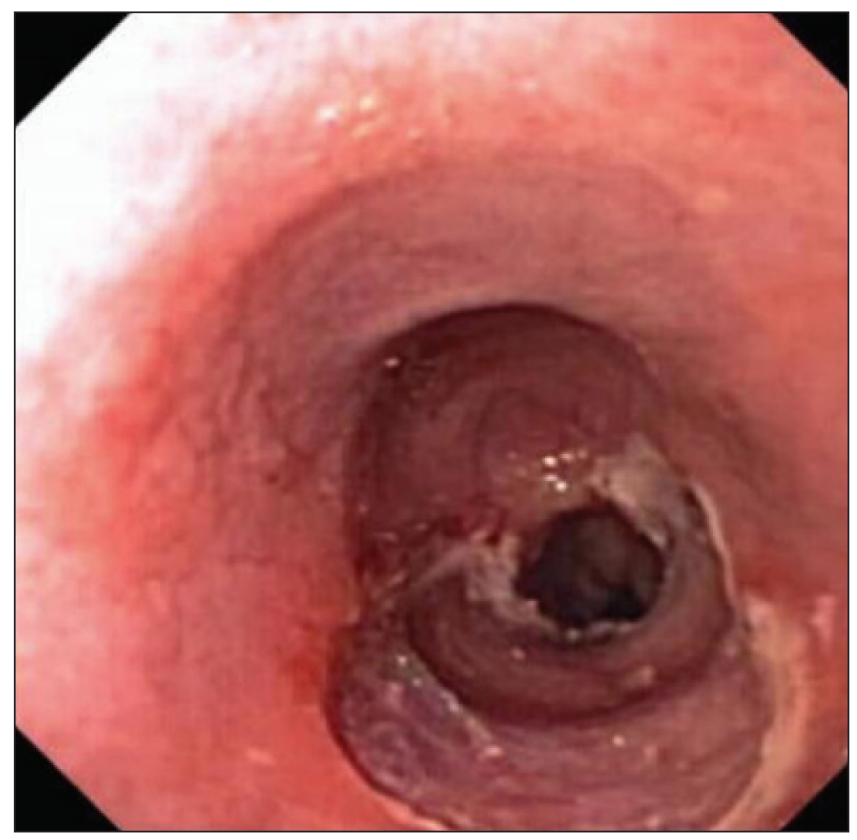

Figure 5) Distal esophagus after endoscopic mucosal resection

outcomes, complication rates and utility of combination therapeutic approaches. Nevertheless, the data supporting the utility of EMR as a diagnostic and therapeutic option are apparent, and should be used in the appropriate setting.

DISCLOSURE: This article was not supported by any grant, contract or other form of financial support.

\section{REFERENCES}

1. Swisher SG, DeFord L, Merriman KW, et al. Effects of operative volume on morbidity, mortality, and hospital use after esophagectomy for cancer. J Thorac Cardiovasc Surg 2000;119:1126

2. van Lanschot JJ, Hulscher JB, Buskens CJ, Tilanus HW, ten Kate FJ, Obertop H. Hospital volume and hospital mortality for esophagectomy. Cancer 2001;91:1574-8.

3. Karl RC, Schreiber R, Boulware D, Baker S, Coppola D. Factors affecting morbidity, mortality, and survival in patients undergoing Ivor Lewis esophagogastrectomy. Ann Surg 2000;231:635-43.

4. Young MM, Deschamps C, Trastek VF, et al. Esophageal reconstruction for benign disease: Early morbidity, mortality, and functional results. Ann Thorac Surg 2000;70:1651-5.

5. Vij R, Triadafilopoulos G, Owens DK, et al. Cost-effectiveness of photodynamic therapy for high-grade dysplasia in Barrett's esophagus. Gastrointest Endosc 2004;60:739.

6. Shaheen NJ, Inadomi JM, Overholt BF, Sharma P. What is the best management strategy for high grade dysplasia in Barrett's oesophagus? A cost effectiveness analysis. Gut 2004;53:1736-44

7. D Comay, G Blackhouse, R Goeree, D Armstrong, JK Marshall. Photodynamic therapy for Barrett's esophagus with high-grade dysplasia: A cost-effectiveness analysis. Can J Gastroenterol 2007;21:217-22.

8. Prasad GA, Wang KK, Buttar NS, et al. Long-term survival following endoscopic and surgical treatment of high-grade dysplasia in Barrett's esophagus. Gastroenterology 2007;132:1226-33.

9. Overholt BF, Lightdale CJ, Wang K, et al. International, multicenter, partially blinded, randomised study of the efficacy of photodynamic therapy (PDT) using porfimer sodium (POR) for the ablation of high-grade dysplasia (HGD) in Barrett's esophagus (BE): Results of 24-month follow-up. Gastroenterology 2003;10:3609. (Abst)

10. Sharma VK, Wang KK, Overholt BF, et al. Balloon-based, circumferential, endoscopic radiofrequency ablation of Barrett's

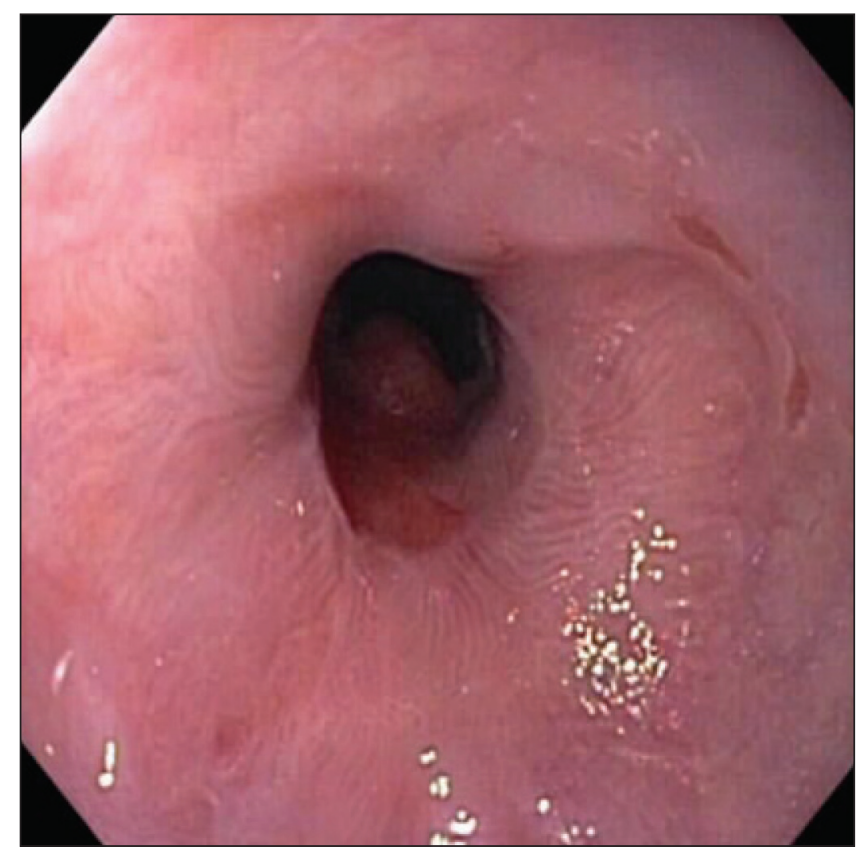

Figure 6) Endoscopic mucosal resection. Healed mucosa

esophagus: 1 -year follow-up of 100 patients. Gastrointest Endosc 2007;65:185-95.

11. Shaheen NJ, Sharma P, Overholt BF, et al. A randomized, multicenter, sham-controlled trial of radiofrequency ablation (RFA) for subjects with Barrett's esophagus containing dysplasia: Interim results of the AIM Dysplasia Trial. Gastroenterology 2008;134:A37. (Abst)

12. Ganz RA, Overholt BF, Sharma VK, et al. Circumferential ablation of Barrett's esophagus that contains high-grade dysplasia: A U.S. Multicenter Registry. Gastrointest Endosc 2008;68:35-40.

13. Fleischer DE, Overholt BF, Sharma VK, et al. Endoscopic ablation of Barrett's esophagus: A multicenter study with 2.5-year follow-up. Gastrointest Endosc 2008;68:867-76.

14. Soetikno RM, Gotoda T, Nakanishi Y, Soehendra N. Endoscopic mucosal resection. Gastrointest Endosc 2003;57:567-79.

15. Pech O, May A, Gossner L, Rabenstein T, Ell C. Management of pre-malignant and malignant lesions by endoscopic resection. Best Pract Res Clin Gastroenterol 2004;18:61-76.

16. Takeshita $\mathrm{K}$, Tani $\mathrm{M}$, Inoue $\mathrm{H}$, et al. Endoscopic treatment of early oesophageal or gastric cancer. Gut 1997;40:123-7.

17. May A, Gossner L, Behrens A, et al. A prospective randomized trial of two different endoscopic resection techniques for early stage cancer of the esophagus. Gastrointest Endosc 2003;58:167-75.

18. Ell C, May A, Gossner L, et al. Endoscopic mucosal resection of early cancer and high-grade dysplasia in Barrett's esophagus. Gastroenterology 2000;118:670-7.

19. Ciocirlan M, Lapalus MG, Hervieu V, et al. Endoscopic mucosal resection for squamous premalignant and early malignant lesions of the esophagus. Endoscopy 2007;39:24-9.

20. Esaki M, Matsumoto T, Hirakawa K, et al. Risk factors for local recurrence of superficial esophageal cancer after treatment by endoscopic mucosal resection. Endoscopy 2007;39:41-5.

21. May A, Gossner L, Pech O, et al. Local endoscopic therapy for intraepithelial high-grade neoplasia and early adenocarcinoma in Barrett's oesophagus: Acute-phase and intermediate results of a new treatment approach. Eur J Gastroenterol Hepatol 2002;14:1085-91.

22. Ell C, May A, Pech O, et al. Curative endoscopic resection of early esophageal adenocarcinomas (Barrett's cancer). Gastrointest Endosc 2007;65:3-10.

23. Takeshita $\mathrm{K}$, Tani $\mathrm{M}$, Inoue $\mathrm{H}$, et al. Endoscopic treatment of early oesophageal or gastric cancer. Gut 1997;40:123-7.

24. Soehendra N, Binmoeller KF, Bohnacker S, et al. Endoscopic snare mucosectomy in the esophagus without any additional equipment: A simple technique for resection of flat early cancer. Endoscopy 1997;29:380-3.

25. Hamada T, Kondo K, Itagaki Y, Nishida J. [Endoscopic mucosal resection for early gastric cancer.] Nippon Rinsho 1996;54:1292-7. 
26. Endo M, Takeshita K, Inoue $\mathrm{H}$. [Endoscopic mucosal resection of esophageal cancer.] Gan To Kagaku Ryoho 1995;22:192-5.

27. Pacifico RJ, Wang KK, Wongkeesong LM, Buttar NS, Lutzke LS. Combined endoscopic mucosal resection and photodynamic therapy versus esophagectomy for management of early adenocarcinoma in Barrett's esophagus. Clin Gastroenterol Hepatol 2003;1:252-7.

28. Suzuki H, Masuda K, Fujisaki J, Okuwaki S. [Endoscopic treatment of gastrointestinal cancers - indication and limitation.] Nippon Rinsho 1996;54:1699-704.

29. Makuuchi H. Endoscopic mucosal resection for early esophageal cancer: Indications and techniques. Dig Endosc 1996;8:175-9.
30. Pech O, Gossner L, May A, et al. Endoscopic resection of superficial esophageal squamous-cell carcinomas: Western experience. Am J Gastroenterol 2004;99:1226-32.

31. Hamada T, Kondo K, Itagaki Y, Nishida J. [Endoscopic mucosal resection for early gastric cancer.]. Nippon Rinsho 1996;54:1292-7.

32. Overholt BF, Wang KK, Burdick JS, et al. Five-year efficacy and safety of photodynamic therapy with Photofrin in Barrett's high-grade dysplasia. Gastrointest Endosc 2007;66:460-8.

33. Soetikno RM, Gotoda T, Nakanishi Y, Soehendra N. Endoscopic mucosal resection. Gastrointest Endosc 2003;57:567-79. 


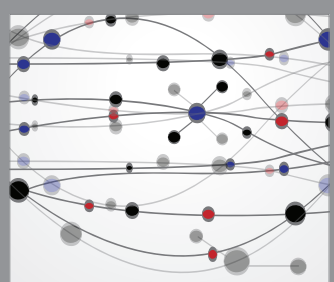

The Scientific World Journal
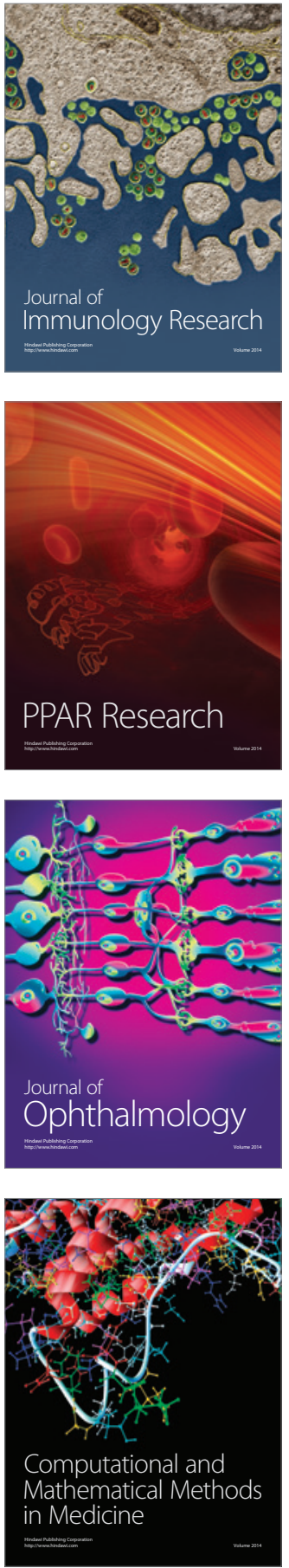

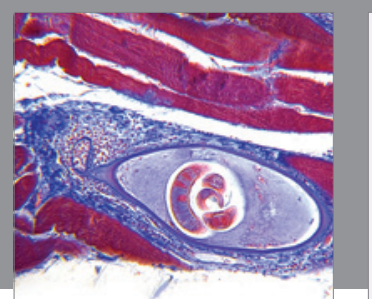

Gastroenterology Research and Practice

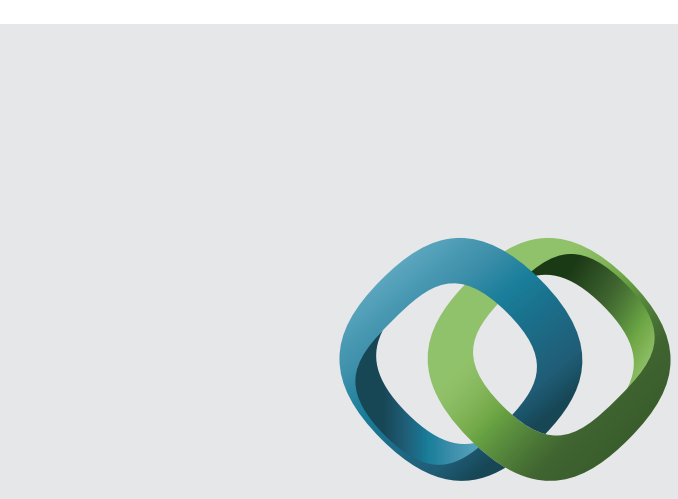

\section{Hindawi}

Submit your manuscripts at

http://www.hindawi.com
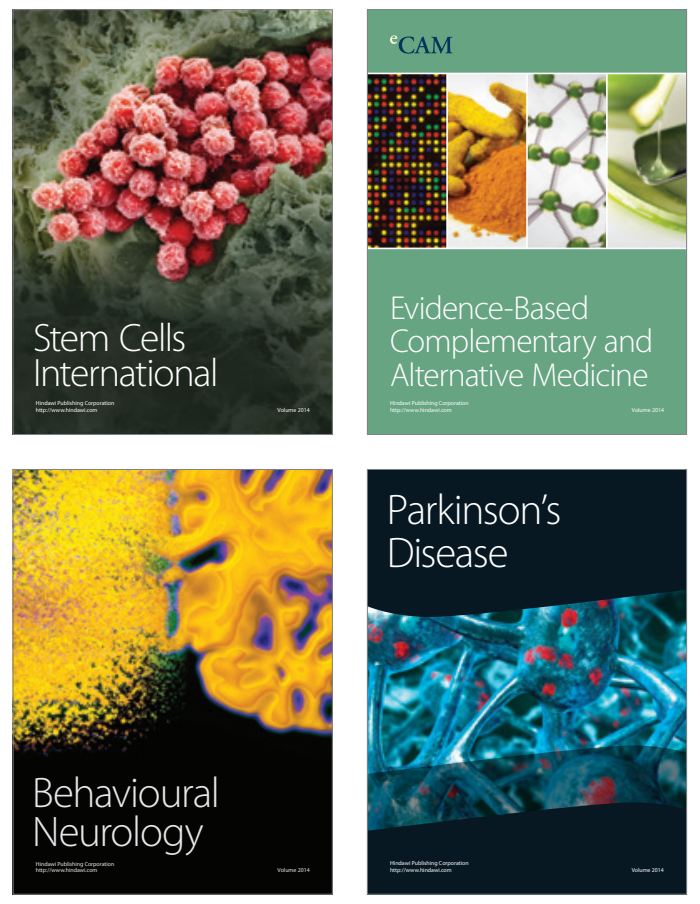
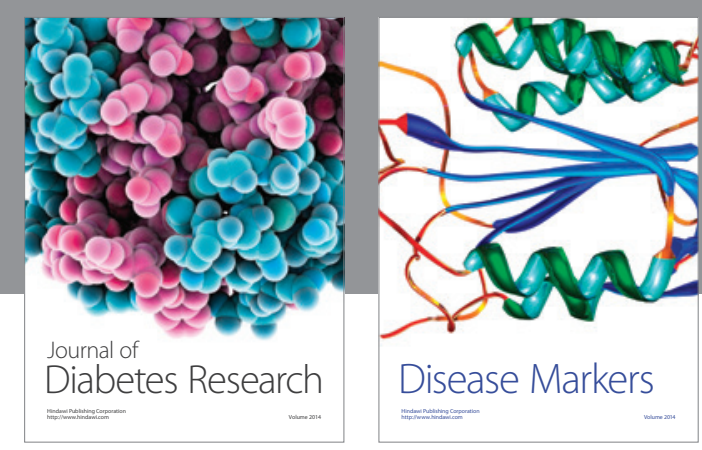

Disease Markers
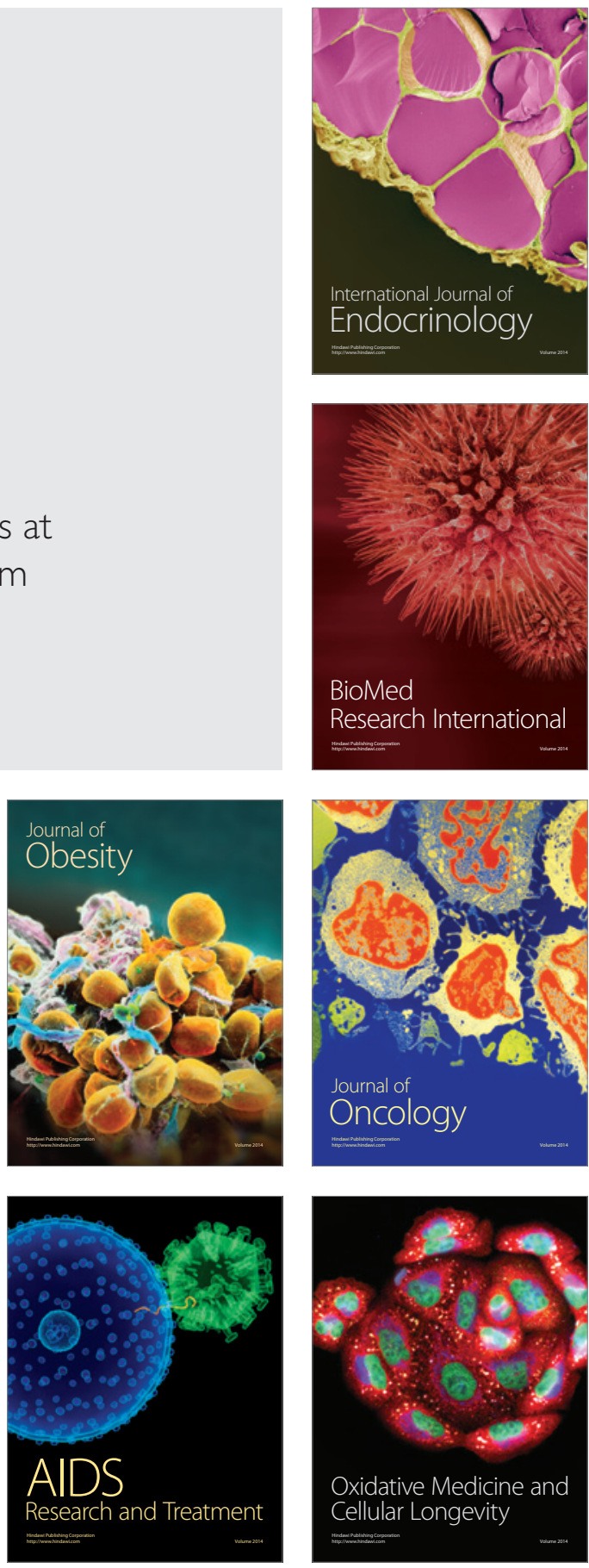